\title{
Guidelines for oral fluid-based surveillance of viral pathogens in swine
}

\author{
Alexandra Henao-Diaz ${ }^{*}$, Luis Giménez-Lirola, David H. Baum and Jeffrey Zimmerman
}

\begin{abstract}
Recent decades have seen both rapid growth and extensive consolidation in swine production. As a collateral effect, these changes have exacerbated the circulation of viruses and challenged our ability to prevent, control, and/or eliminate impactful swine diseases. Recent pandemic events in human and animal health, e.g., SARS-CoV-2 and African swine fever virus, highlight the fact that clinical observations are too slow and inaccurate to form the basis for effective health management decisions: systematic processes that provide timely, reliable data are required. Oral fluid-based surveillance reflects the adaptation of conventional testing methods to an alternative diagnostic specimen. The routine use of oral fluids in commercial farms for PRRSV and PCV2 surveillance was first proposed in 2008 as an efficient and practical improvement on individual pig sampling. Subsequent research expanded on this initial report to include the detection of $\geq 23$ swine viral pathogens and the implementation of oral fluid-based surveillance in large swine populations (> 12,000 pigs). Herein we compile the current information regarding oral fluid collection methods, testing, and surveillance applications in swine production.
\end{abstract}

Keywords: Oral fluids, Surveillance, Viral diseases, ELISA, RT-PCR

\section{Background}

Between 1968 and 2018, the worldwide swine inventory increased from 550 to 981 million pigs (+78\%), with the most marked growth in the developing regions of the world, i.e., Africa $+504 \%$, Asia $+137 \%$, and South America $+59 \%$ [1]. Over the same period, albeit with regional variations, the majority of pig production moved from smaller, farrow-to-finish enterprises into larger, multisite production systems that are highly dependent upon the interchange of animals, people, equipment, and sundries between production sites; a process that connects farms and moves infectious agents between them [2, 3]. From an animal health perspective, larger pig populations combined with extensive interactions between production sites produce conditions that promote the circulation of infectious diseases within/between farms

* Correspondence: yulyh@iastate.edu

Department of Veterinary Diagnostic and Production Animal Medicine,

College of Veterinary Medicine, Veterinary Medical Research Institute, lowa

State University, Ames, lowa 50011, USA while simultaneously challenging our ability to control them $[4,5]$. From a business perspective, these changes have limited our ability to avoid or control the economic impact of adverse disease events and, thus, place producers at greater financial risk [6].

In 1982, Calvin Schwabe, responding to the emerging problem of multi-factorial "production diseases", noted that the simple causal models described by Koch and Pasteur no longer applied, i.e., predisposing causes, latency, carriers, opportunistic pathogens $[4,5]$. To adapt to these new conditions, he recommended on-going surveillance to establish baseline levels of disease "against which effects of intervention (control) efforts can be measured". No one followed Schwabe's advice - perhaps because the serum-based surveillance methods of the time were too cumbersome and expensive for routine use in commercial swine herds.

Since the publication of Schwabe's comments, a variety of diagnostic alternatives to serum have been described, e.g., tonsil scrapings [7], tonsil biopsies [8], tonsil swabs 
[9], blood swabs [10], nasal swabs [11], nasal wash [12], buccal swabs [13], probang samples [14], and oral fluids [15]. These specimens offer new possibilities for surveillance, but are they diagnostically equivalent? Direct comparisons are rare in the published literature, but it is broadly recognized that the concentration of diagnostic targets changes in various diagnostic specimens over the course of an infection with corresponding specimendependent changes in test performance. Thurmond (2003), described this process as "disease transition stages", and the corresponding changes in diagnostic performance for specific combinations of specimen and test as "diagnostic transition stages". Thus, Henao-Diaz et al. (2020) showed that the probability of detecting porcine reproductive and respiratory syndrome virus (PRRSV) ribonucleic acid (RNA) in serum by reverse transcription polymerase chain reaction (RT-PCR) at 98 days post infection (DPI) was $\sim 2 \%$ versus $\sim 30 \%$ in lymphoid tissues (tonsil) by bioassay [16]. A complete discussion of the diagnostic performance issues intrinsic to various specimen is beyond the scope of this review, but these differences must be considered in designing sampling/testing protocols. With this caution in mind, the objective of this review is to present the fundamental concepts of oral fluid-based diagnostics and recommendations for their use in the field.

\section{Definitions}

Saliva, mixed saliva, and oral fluid differ by composition and the method of collection [17]. Saliva is primarily produced by three pairs of salivary glands (parotid, submandibular, sublingual) and is collected using specific techniques, including cannulation of the salivary ducts. Parotid glands produce a serous secretion; submandibular and sublingual glands produce seromucous secretions rich in proteins and other serum-derived components $[18,19]$. Mixed or whole saliva, the fluid collected from the buccal cavity by spitting or drainage, is a mixture of saliva and other constituents, i.e., mucosa transudate, gingival crevicular exudate, cell detritus, tracheal-nasal secretions, food debris, gastrointestinal reflux, and serum-derived compounds [18, 19]. Oral fluid, as defined by Atkinson et al. (1993), is the liquid collected by placing an absorptive device in the buccal cavity. Various commercial devices are available for collecting oral fluids from humans, but oral fluids are usually collected either from one individual pig or a group of pigs by suspending a length of cotton rope in the pen, then recovering the individual fluid or the aggregate fluid by compressing the rope [20].

\section{Oral fluids}

As reviewed by Prickett and Zimmerman (2010), research on immunologic and diagnostic aspects of oral fluids from humans and domestic animals began roughly a century ago and has included work on some of the most impactful diseases of humans and livestock, e.g., poliovirus and food-and-mouth disease virus (FMDV). A key event in this timeline was the recognition that both human immunodeficiency virus (HIV) and HIV antibody (1986) were present in oral fluids from infected individuals; a finding that led to the development of commercial oral fluid HIV antibody tests (1995) [21]. For both humans and domestic animals, there are two major issues for oral fluid diagnostic assays: (1) antibody assays must account for the lower antibody concentration in oral fluid versus serum [22], and (2) PCR assays must account for the unique characteristics of the oral fluid matrix. In sum, diagnostic assays are not directly interchangeable between specimens and must be adapted to the oral fluid matrix to provide the best diagnostic performance $[23,24]$.

Oral fluid is a dynamic and complex matrix consisting of water, hormones, metabolites, electrolytes, enzymes, antibodies, mucins, and an assortment of other proteins $[18,25]$. Oral fluid necessarily contains components produced in buccal-associated tissues, e.g., saliva and antibodies produced by plasma cells located in salivary glands and tonsils [26]. In addition, the oral cavity is covered with a protective layer of semipermeable mucosa tightly bound to the underlying connective tissue. The semipermeability of these tissues facilitates a continuous exchange between the circulatory/lymphatic systems and the buccal cavity by both passive and active processes: 1) ultrafiltration of small molecules through intercellular gap junctions, e.g., water, ions, hormones, urea; 2) transudation of components from capillaries associated with the mucosa; and 3) selective and/or receptor-mediated transport of larger molecules and lipophilic compounds from capillaries, e.g., antibodies, hormones, and other proteins. Likewise, a dynamic exchange of inorganic components, e.g., bicarbonate, chlorine, potassium, and phosphate, occurs as fluid moves through the salivary ducts, ultimately affecting the $\mathrm{pH}$ and tonicity of buccal fluids [19, 27].

In addition to physiologically intrinsic constituents, oral fluids usually contain enteric micro-organisms, feed components, drug compounds and metabolites recovered by the pigs from their environment. That is, as a result of pigs' normal exploratory behavior, i.e., smelling, tasting, biting, and rooting, environmental diagnostic targets are collected in the buccal cavity [28] - some of which are subsequently passed onto the rope and into the oral fluid specimen. This is not a negative attribute of the specimen; to the contrary, the presence of such material broadens the diagnostic utility of the oral fluid sample $[29,30]$. 


\section{Diagnostic potential of oral fluid specimens Detection of antibody in oral fluids}

Immunoglobulins (Ig) M, IgA, and IgG reach the buccal cavity by passive diffusion and/or via receptor-mediated transportation from the circulatory and/or lymphatic systems [31, 32]. In addition, all classes of antibody, including secretory IgA, are produced by plasma cells located in tissues associated with the buccal cavity $[19,23]$. Serum and oral fluid antibody isotype kinetics are similar, as demonstrated in studies on the antibody responses to African swine fever virus (ASFV) [33], classical swine fever virus (CSFV) [34], influenza A virus (IAV) [35], porcine circovirus type 2 (PCV2) [36], and PRRSV [37]. As observed in serum, IgM is detected in oral fluids before IgA and IgG, but has a shorter half-life than other isotypes. IgA (primarily secretory IgA) appears earlier than IgG but usually IgG is the preferred target of oral fluid enzyme-linked immunosorbent assays (ELISAs) because its longer half-life and because usually provides for more diagnostically sensitive and specific assays [38, 39] (Fig. 1). Importantly, the isotype-specific responses against each pathogen must be investigated during the process of assay development because there are exceptions to this general rule. Thus, Bjustrom-Kraft et al. (2016) found that a porcine epidemic diarrhea virus (PEDV) oral fluid ELISA based on IgA detection provided the best diagnostic performance [41] and Rotolo et al. (2018a) demonstrated that an IgM-IgA PRRSV oral fluid ELISA detected infection in young pigs, even in the presence of circulating maternal IgG PRRSV antibody [40] (Fig. 1).

\section{Detection of nucleic acids in oral fluids}

PCR (or RT-PCR, depending on the genetic composition of the pathogen considered) is a general approach for detecting nucleic acids that has been adapted to a variety of diagnostic specimens, including oral fluids (Table 1). Most typically, the detection of viral nucleic acids in oral fluids is coincident with viremia or viral replication in buccal tissues and/or the upper respiratory tract, but viruses in the environment will also be detected. For example, PEDV, porcine coronavirus (PCV2), and porcine delta coronavirus (PDCoV) shed in feces were likewise detected in oral fluids $[41,51,54]$.

PCR is considered the best method for "early" detection of viral infections in oral fluids, but "early" varies among pathogens. For example, FMDV replicates in the soft palate, pharyngeal epithelium, and tonsils, and may be detected in oral fluids at $\geq 1$ DPE [65]. Pseudorabies virus (PRV) first replicates in epithelial cells of the upper respiratory tract and was detected in oral fluids at $\geq 3$ DPE [61]. CSFV replicates in tonsils and lymphoid nodes has been detect in oral fluids at $\geq 5$ DPE [66]. A further complication, is the variation in detection by PCR observed among strains of the same virus and even among specimens from the same animals. Weesendorp et al. (2009) described marked differences in detection among

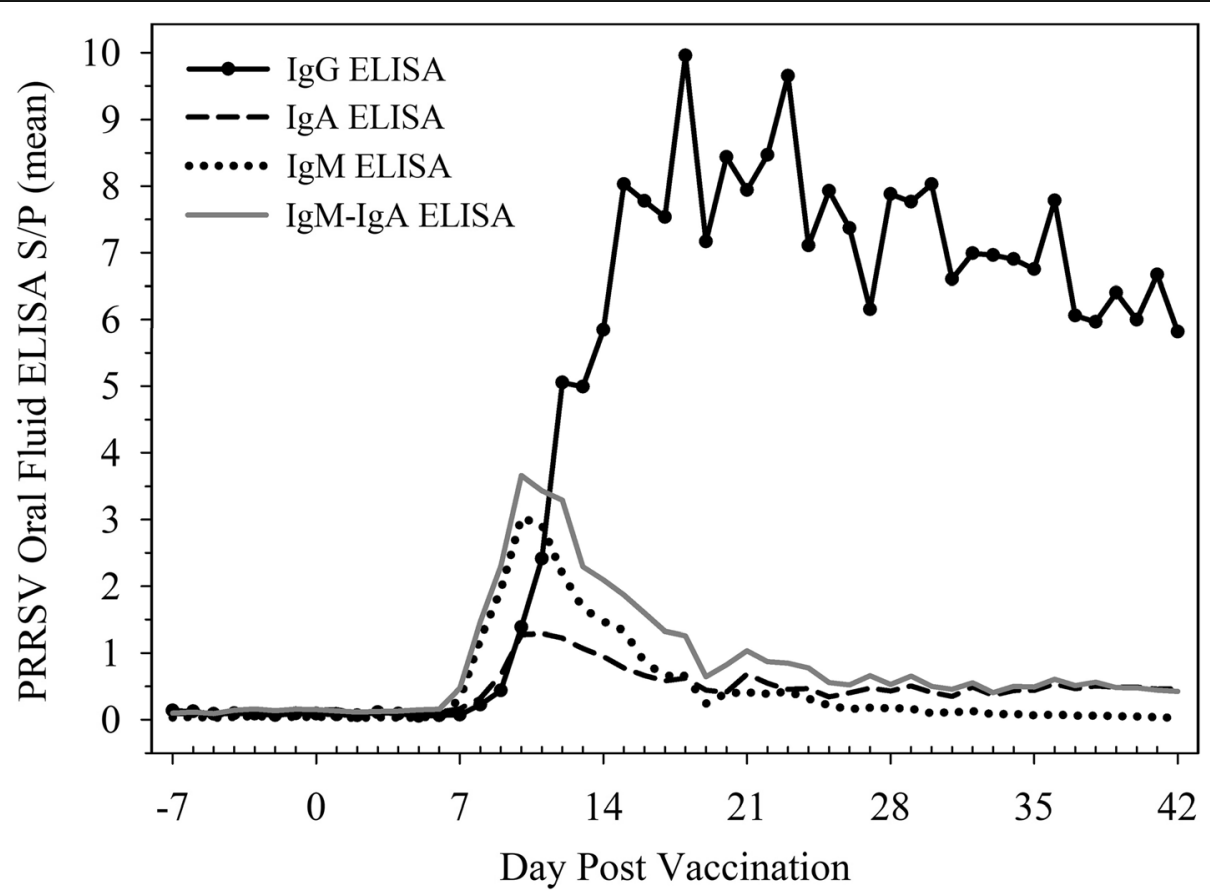

Fig. 1 PRRSV antibody kinetics in oral fluid samples collected from 12 pigs vaccinated with a modified-live virus vaccine over the course of 50 days ( 7 to 42 DPV). Reprinted from Rotolo et al. (2018) [40], Veterinary Microbiology 214, 13-20 (copyright 2017) with permission from Elsevier (4812031256013) 
Table 1 Swine virus-specific nucleic acid and antibody detection reported in oral fluids ${ }^{a}$

\begin{tabular}{|c|c|c|}
\hline Pathogen $^{b}$ & Nucleic acid detection & Antibody detection \\
\hline APPV & Schwarz et al., 2017 [42] & not reported \\
\hline ASFV & Grau et al., 2015 [43] & Giménez-Lirola et al., 2016 [33] \\
\hline CSFV & Dietze et al., 2017 [44] & Panyasing et al., 2018c [34] \\
\hline FMDV & Senthilkumaran et al., 2017b [45] & Poonsuk et al., 2018 [46] \\
\hline HEV & Plut et al., 2020 [47] & not reported \\
\hline IAV & Goodell et al., 2013 [11] & Panyasing et al., 2014 [48] \\
\hline JEV & Lyons et al., 2018 [49] & not reported \\
\hline NIPAH virus & Kasloff et al., 2019 [50] & not reported \\
\hline PCV2 & Wonziak et al., 2019 [51] & Prickett et al., 2011 [36] \\
\hline PCV3 & Guo et al., 2019 [52] & Bai et al., 2020 [53] \\
\hline PDCoV & Homwong et al., 2016 [54] & not reported \\
\hline PEDV & Bjustrom-Kraft et al., 2016 [41] & Bjustrom-Kraft et al., 2016 [41] \\
\hline PHEV & Mora-Díaz et al., 2019 [55] & Mora-Díaz et al., 2019 [55] \\
\hline PKV & Gauger et al., 2020 [56] & not reported \\
\hline PPIV1 & Park et al., 2019 [57] & not reported \\
\hline PPV & Milek et al., 2019 [58] & not reported \\
\hline PRCV & Magtoto et al., 2019 [59] & Magtoto et al., 2019 [59] \\
\hline PRRSV & Decorte et al., 2015 [60] & Henao-Diaz et al., 2019 [38] \\
\hline PRV & Panyasing et al., 2018a [61] & Panyasing et al., 2018a [61] \\
\hline SVA & Hole et al., 2019 [62] & Hole et al., 2019 [62] \\
\hline SVDV & Senthilkumaran et al., 2017a [63] & Senthilkumaran et al., 2017a [63] \\
\hline TGEV & Magtoto et al., 2019 [59] & Magtoto et al., 2019 [59] \\
\hline TTV & Ramirez et al., 2012 [64] & not reported \\
\hline
\end{tabular}

${ }^{a}$ Table 1 provides examples of the detection of virus-specific nucleic acids and/or antibody in swine oral fluids, i.e., is not comprehensive

${ }^{\mathrm{b}}$ Acronyms defined in the list of abbreviations and terms

3 strains of CSFV in a comparison of 8 different specimen types; feces, serum, and buccal specimens among them [67]. Similarly, Pepin et al., (2015) reported both isolate - and specimen-dependent differences in PRRSV detection in boars inoculated under experimental conditions [10] (Table 2).

\section{Detection of infectious virus in oral fluids}

With mixed success, some of the key viral pathogens of swine (FMDV, SVDV, IAV, SVA, and PRRSV) have been

Table 2 Early detection of PRRSV by PCR as a function of specimen and day post inoculation ${ }^{a}$

\begin{tabular}{llllllll}
\hline Specimen & \multicolumn{7}{l}{ Positivity (\%) by day post inoculation } \\
\cline { 2 - 8 } & 1 & 2 & 3 & 4 & 5 & 6 & 7 \\
\hline Serum & 36.5 & 79.1 & 89.5 & 93.8 & 95.2 & 97.4 & 99.9 \\
Blood swab & 30.3 & 73.3 & 79.4 & 86.7 & 87.9 & 99.9 & 99.9 \\
Oral fluid & 3.6 & 59.0 & 89.4 & 97.6 & 99.9 & 99.9 & 99.9
\end{tabular}

${ }^{a}$ Probability calculated using a binomial logistic regression model with estimates obtained using the least square methods. Reprinted from Pepin et al. (2015) Transboundary and Emerging Diseases 62, 295-304 (copyright 2013) with permission from John Wiley and Sons (4816070894659) isolated from oral fluids under research conditions [7, $24,45,62,63]$. Virus isolation is not routinely used in surveillance and will not be addressed in this review. If virus recovery is an objective, it should be attempted on optimally-collected specimens from clinically-affected individuals.

\section{Similar ... but not the same}

Specimens that seem similar to oral fluids may have very different diagnostic characteristics. For example, Pepin et al. (2015a) compared testing results among oral fluids and "frothy saliva", i.e., the buccal foam produced mature boars, in 15 boars for 14 days following administration of a commercial modified-live virus PRRSV vaccine. Between 1 to 14 days post vaccination (DPV), $71 \%(50 / 70)$ of oral fluids and 19\% $(13 / 70)$ of frothy saliva samples were positive for PRRSV RNA. Between 8 to 14 DPV, PRRSV ELISA antibody positivity rates were $69 \%(24 / 35)$ for oral fluids and $0 \%(0 / 35)$ for frothy saliva [10].

Similarly, differences in detection rates have been reported for pen-based oral fluids versus individual 
pig buccal or nasal swabs for animals inoculated with FMDV, IAV, Senecavirus A (SVA), and swine vesicular disease virus (SVDV) [45, 62, 63, 68]. In each study, oral fluids provided higher RNA detection rates than swabs (Table 3). These results may be explained by the fact that swabs inherently collect a smaller amount of target and typical collection procedures further dilute the sample. In particular, placing the swab in 1-2 $\mathrm{ml}$ of medium for transport to the laboratory reduces the concentration of the target in the sample and, therefore, the probability of detection [68]. In the case of buccal swabs, physiology also comes in to play. Salivary glands, ducts, and small vessels are innervated by sympathetic (fight-or-flight) and parasympathetic systems. The process of restraining a pig to collect the buccal swab induces a stress response that includes vasoconstriction of vessels supplying the buccal mucosa, salivary glands, and salivary ducts. This response reduces the flow of fluids to the mouth ("dry mouth") and alters buccal fluid composition $[19,26,27]$.

\section{How to collect oral fluids}

Oral fluid sample collection is possible because it is consistent with pigs' natural behavior. Pigs are curious and will readily explore unfamiliar objects, e.g., a rope dangling in the pen, by biting and chewing [28]. Pig are also highly social and if one member of the group interacts with the rope other pigs will follow [69, 70]. Thus, because it is voluntary and does not require animal restraint, oral fluid sampling is a welfarefriendly process with no discomfort or stress to pigs or animal caretakers [26]. Numerous videos illustrating the oral fluids collection process are available on the internet [71], but the following comments may be helpful.

\section{Oral fluid sampling basics}

Oral fluid samples are readily collected from groups of pigs $\geq 21$ days of age by providing access to a suspended length of cotton rope for $\sim 30 \mathrm{~min}[64,72,73]$. The majority of oral fluid research has been done on pens of 25 pigs, in which case one rope will provide an oral fluid sample representing $\sim 80 \%$ of the animals in a $30 \mathrm{~min}$ sampling [74, 75]. Samples are most easily collected in the morning when pigs first awake and prior to feeding, if on a feeding schedule $[69,75]$. Allow 45 to $60 \mathrm{~min}$ of sampling time at the first collection for pigs to learn the process. Thereafter, the pigs will remember and will respond quickly to the presence of the hanging rope and 30 min should be sufficient to obtain the sample $[15,69$, 73]. To harvest the sample, remove the rope, place the wet portion of the rope inside a plastic bag, extract the oral fluid (by hand or wringer), and decant the sample into a container [76]. Oral fluids can likewise be collected from individual animals, as is done in sows, gilts, or some boar studs. However, sampling individuals tends to be less successful than group sampling, particularly older sows and boars, although "training" the animals (see description in trouble-shooting section) can be helpful $[15,73,75]$.

As opposed to nylon, hemp, or polyester, cotton rope provides the best overall diagnostic utility for antibody and nucleic acid detection [22,39]. Three-stranded cotton rope $\sim 1.6 \mathrm{~cm}$ in diameter is optimal for oral fluid collection in animals $\geq 40 \mathrm{~kg}$, but younger animals prefer smaller diameter rope $(\leq 0.8 \mathrm{~cm})$. Alternatively, individual strands of larger diameter rope can be used to meet the younger pigs' thinner rope preference [70, 73].

In the field, ropes are commonly suspended from pen gates, thereby avoiding the need to enter the pen either to hang or collect the rope. However, providing additional space around the rope will increase the number

Table 3 Difference on nucleic detection rates in oral fluids and individual buccal or nasal swabs

\begin{tabular}{|c|c|c|c|c|c|c|c|c|c|c|c|}
\hline \multirow[t]{2}{*}{ Virus } & \multirow[t]{2}{*}{ Specimen } & \multicolumn{10}{|c|}{ Rate of detection (\%) by Day post inoculation (DPI) } \\
\hline & & 1 & 2 & 3 & 4 & 5 & 6 & 8 & 10 & 12 & 15 \\
\hline \multirow[t]{2}{*}{$\mathrm{FMD}^{\mathrm{a}}$} & OF & 75 & 100 & 100 & 100 & 100 & 75 & * & * & 100 & * \\
\hline & Swabs & 4 & 33 & 61 & 100 & 89 & 50 & * & * & 25 & * \\
\hline \multirow[t]{2}{*}{$\mid A V^{b}$} & OF & 100 & 100 & 75 & 25 & 38 & 29 & 29 & 17 & 0 & 0 \\
\hline & Swabs & 100 & 100 & 100 & 75 & 13 & 0 & 0 & 0 & 0 & 0 \\
\hline \multirow[t]{2}{*}{ PRRSV } & OF & 0 & 20 & 60 & 80 & 100 & 100 & 100 & 80 & 100 & 20 \\
\hline & Swabs & 0 & 0 & 0 & 40 & 20 & 60 & 0 & 20 & 20 & 20 \\
\hline \multirow[t]{2}{*}{$S V A^{d}$} & OF & * & 67 & * & 100 & * & 100 & 100 & 100 & * & 100 \\
\hline & Swabs & * & 92 & * & 100 & * & 75 & 67 & 75 & * & 8 \\
\hline
\end{tabular}

\footnotetext{
* No data reported at the DPI or one day before or after the DPI
}

${ }^{a}$ Mean of positivity rate estimated on pen-based oral fluids and individual buccal swabs collected from 24 pigs divided in 4 groups [45]

b Mean of positivity rate estimated on pen-based oral fluids and individual nasal swabs collected from 8 pigs divided in 3 groups [68]

c Mean of positivity rate estimated on pen-based oral fluids and individual buccal swabs (frothy saliva) collected from 15 pigs, sampling 3 rolling 5 -pigs groups [10]

${ }^{\mathrm{d}}$ Mean of positivity rate estimated on pen-based oral fluids and individual buccal swabs collected from 12 pigs divided in 3 groups [62] 
of pigs interacting with the rope at any one time [74, 76]. Strategies for providing additional space include hanging the rope from a rafter or from a bracket extending from a side of the pen $[64,77]$.

\section{Take care of the sample}

The stability of antibody in swine oral fluids is poorly described and the data available is limited to PRRSV. Antibody degradation in oral fluids is temperaturedependent, e.g., PRRSV ELISA S/P (sample-to-positive) ratios in samples stored at $4{ }^{\circ} \mathrm{C}$ were stable for $12-14$ days, with faster degradation coinciding with increasing temperature. No antibody was detected in oral fluid after $72 \mathrm{~h}$ at $30^{\circ} \mathrm{C}[78,79]$. Freezing oral fluid samples for subsequent PRRSV antibody testing is a safe option, i.e., antibody oral fluid is highly resistant to "freeze-thaw" degradation, as indicated by consistent PRRSV ELISA S/ $P$ values in samples subjected to repeated "freeze-thaw" cycles (unpublished data).

Likewise, little quantitative information is available regarding the degradation of intact virus or viral nucleic acids in oral fluids. Calculations based on published data [79] estimated the half-life of RT-PCRdetectable PRRSV RNA in oral fluids as approximately $13 \mathrm{~h}\left(30^{\circ} \mathrm{C}\right), 42 \mathrm{~h}\left(20^{\circ} \mathrm{C}\right)$, and $\geq 14$ days $(<$ $10^{\circ} \mathrm{C}$ ). Unlike antibody, nucleic acids are susceptible to freeze-thaw degradation. This effect is undoubtedly not uniform across viruses, i.e., IAV RNA is particularly susceptible to this effect (unpublished data). To achieve the best results on frozen samples, Weiser et al. (2018) showed that thawing frozen oral fluids overnight at $4{ }^{\circ} \mathrm{C}$ produced more PRRSV RT-PCR positive results than thawing at $22^{\circ} \mathrm{C}(94 \%$ vs $80 \%$ on matched samples, respectively) [80].

In summary, to maintain diagnostic targets (antibody and/or nucleic acids) when collecting oral fluids in the field, chill samples as soon as possible after collection by refrigeration $\left(4^{\circ} \mathrm{C}\right)$ or by placing the samples in coolers containing crushed ice or ice packs. The cold chain should be maintained throughout transport and in the laboratory until tested. If it is not possible to maintain the cold chain and/or testing cannot be completed within 7 days, samples should be frozen $\left(\leq-20^{\circ} \mathrm{C}\right)$. However, multiple freeze-thaw cycles should be avoided, particularly in the case of samples intended for PCR testing. It follows that, long-term storage in self-defrosting freezers must be avoided because of temperature fluctuations during the defrost cycle. Attempts to stabilize oral fluids antibody using antimicrobials or oral fluids RNA using nucleic acid stabilizers showed no improvement when compared to chilling $\left(4^{\circ} \mathrm{C}\right)$ samples $[79,81,82]$. The use of Flinders Technology Associates (FTA) cards to preserve oral fluids PRRSV RNA was effective, but showed significant loss of RT-PCR sensitivity [83].

\section{Trouble-shooting oral fluid collection}

When collected under clean conditions, e.g., experimental settings, oral fluids are straw-colored and translucent. When collected under field conditions, oral fluids contain environmental contaminates, e.g., manure and feed, to varying degrees (Fig. 2a-e). Sample contamination may be reduced by not allowing the rope to reach the floor, i.e., set the bottom of the rope at pigs' shoulder height [15, 74]. In the laboratory, organic contaminants per se do not affect the diagnostic properties of the sample (nucleic acid or antibody detection), but cleaner samples are easier to process and more amenable to accurate pipetting. Variable centrifugation protocols for swine oral fluids have been reported in literature, e.g., 12,000 $\mathrm{g} \times 8 \mathrm{~h}$ [37], $14,000 \mathrm{~g} \times 30 \mathrm{~s}$ [84], $9000 \mathrm{~g} \times 10 \mathrm{~min}$ [64]. Gibert et al. (2017) reported that centrifuging at $15000 \mathrm{~g} \times 15 \mathrm{~min}$ improved PRRSV nucleic acids detection in spiked samples compared to no centrifuged samples [85]. However, a "gentle" centrifugation protocol $(3000 g \times 5-10 \mathrm{~min})$ should be helpful in eliminating large particles. Efforts to fully remove suspended particulates, e.g., chemical
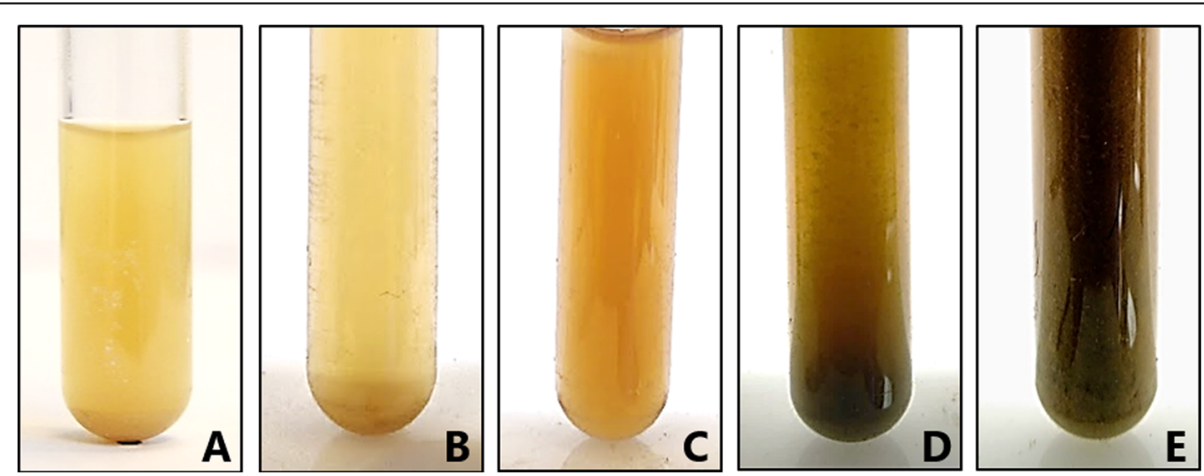

Fig. 2 Appearance variability among swine oral fluid samples. a Oral fluids collected under experimental conditions. b Field oral fluids collected from individual-pen held pigs. c-e Field oral fluids collected from pen-held group of pigs 
clarification [78], filtration [22], or prolonged centrifugation have shown no benefit in terms of improved diagnostic performance and may rise the sample processing time.

Some pigs, particularly younger pigs, may be reluctant to approach the hanging rope upon their first exposure. Enticing pig participation by providing rope with flavored (fruits juice, sucrose,) [86], colored, or aromatic substances (garlic, unpublished data) has generally not been rewarding with the exception of one report showing a higher oral fluid collection success rate in suckling piglets exposed to rope treated with a commercial baby pig supplement [70]. However, the initial reluctance to approach the rope can often be overcome by training the pigs, i.e., placing the rope on the floor for the pigs to investigate $(20 \mathrm{~min})$, slowly dragging the rope to the spot where it will be hung (the pigs will follow the "tail" of the rope), and then hanging a new clean rope [38, 74]. As is desirable for working with pigs, this process should be done quietly and without sudden movements so as to avoid startling the animals. Some individually housed adults may also be trained (as described above) to oral fluid collection [15, 75].

Little information is available on collecting oral fluids from pigs housed with organic bedding or under free range conditions, i.e., situations in which the presence of a hanging rope may not attract the pigs' attention [75, 87]. In free range animals, oral fluids have been collected using "samplers" consisting of short lengths $(\sim 10 \mathrm{~cm})$ of rope embedded with a cereal-based bait matrix. Investigators have reported that the animals chewed the samplers, dropped them on the floor, and the next pig repeated the process, thereby providing an "aggregate" specimen [44, 65]. Under experimental conditions, this approach provided for better CSFV or FMDV nucleic acids detection than oropharyngeal, nasal, or buccal swabs [44, $65,88]$. Several rope samplers can be provided to a group of pigs. Samplers should be recovered while still moist to maximize oral fluid collection.

\section{In the field}

\section{Detection at the pen level}

As the proportion of infected pigs in a pen increases, the probability of a positive test result (PCR or ELISA) likewise increases. Olsen et al. (2013b) quantified this relationship for PRRSV by establishing prevalence ( 0 to $36 \%$ ) in pens of 25 pigs using MLV PRRSV vaccinated pigs (14 days prior). Oral fluids were then collected and tested for PRRSV RNA and antibody. For this review, data from Olsen et al. (2013b) were analyzed in a logistic regression model to establish the relationship between the positive oral fluid testing results (RNA or antibody) and within pen prevalence (Table 4). Data on detection by prevalence in pens of larger size is lacking. This is a concern because the industry is trending toward larger pens (up to 500 pigs in some systems). If the population of interest is a pen(s), current information would suggest using one rope per 25 pigs in order to optimize the proportion of pigs interacting with the ropes and, thereby, increase the probability of detection $[74,77,87]$.

\section{Detection at the barn and site levels}

The surveillance objective in larger populations is determining the status of the barn or the production site (multiple barns). Rotolo et al. (2017) estimated the barn-level probability of PRRSV detection as a function of sample size, sampling location within the barn, and PRRSV prevalence (positive pens) [90]. Figure 3, derived from data in Rotolo et al. (2017), provides guidelines regarding the association between prevalence (number of positive pens) and the number of oral fluid samples required to detect PRRSV in the barn population. For example, collecting 6 pen-based oral fluids in a barn with $\sim 1000$ pigs would provide for a $\sim 50 \%$ probability of PRRSV detection when $10 \%$ of pens are positive. However, this probability increases to $\sim 80 \%$ when the number of positive pens increases to $25 \%$. The original estimates were based on detection of RNA, but similar estimates would be expected for antibody. Likewise, a similar association would be expected for other viral pathogens.

Table 4 Probability of PRRSV detection as a function of within pen prevalence

\begin{tabular}{|c|c|c|c|c|}
\hline \multirow{2}{*}{$\begin{array}{l}\text { Within } \\
\text { pen } \\
\text { prevalence }\end{array}$} & \multicolumn{2}{|c|}{ Probability (\%) of detection with one oral fluid sample $(95 \% \mathrm{Cl})^{\mathrm{a}}$} & \multicolumn{2}{|c|}{ Serum samples to match oral fluid probability ${ }^{b}$} \\
\hline & RT-PCR & ELISA & RT-PCR & ELISA \\
\hline $5 \%$ & $31 \%(9,67)$ & $17 \%(6,38)$ & 8 & 5 \\
\hline $10 \%$ & $79 \%(48,94)$ & $59 \%(37,77)$ & 11 & 5 \\
\hline $20 \%$ & $98 \%(88,100)$ & $94 \%(82,98)$ & 13 & 10 \\
\hline $30 \%$ & $100 \%(96,100)$ & $99 \%(93,100)$ & 12 & 10 \\
\hline $40 \%$ & $100 \%(98,100)$ & $100 \%(97,100)$ & 10 & 9 \\
\hline $50 \%$ & $100 \%(99,100)$ & $100 \%(98,100)$ & 9 & 8 \\
\hline
\end{tabular}

${ }^{a}$ Probability of detection in oral fluids estimated by logistic regression (pen as random effect) from data reported in Olsen et al. (2013b). Within pen prevalence established by placing PRRSV-positive pigs (14 days after MLV vaccination) in pens of PRRSV-negative pigs to achieve 25 pigs per pen [89]

${ }^{\mathrm{b}}$ Number of serum samples required to match the probability of detection for one oral fluid sample was estimated using a hypergeometric distribution 


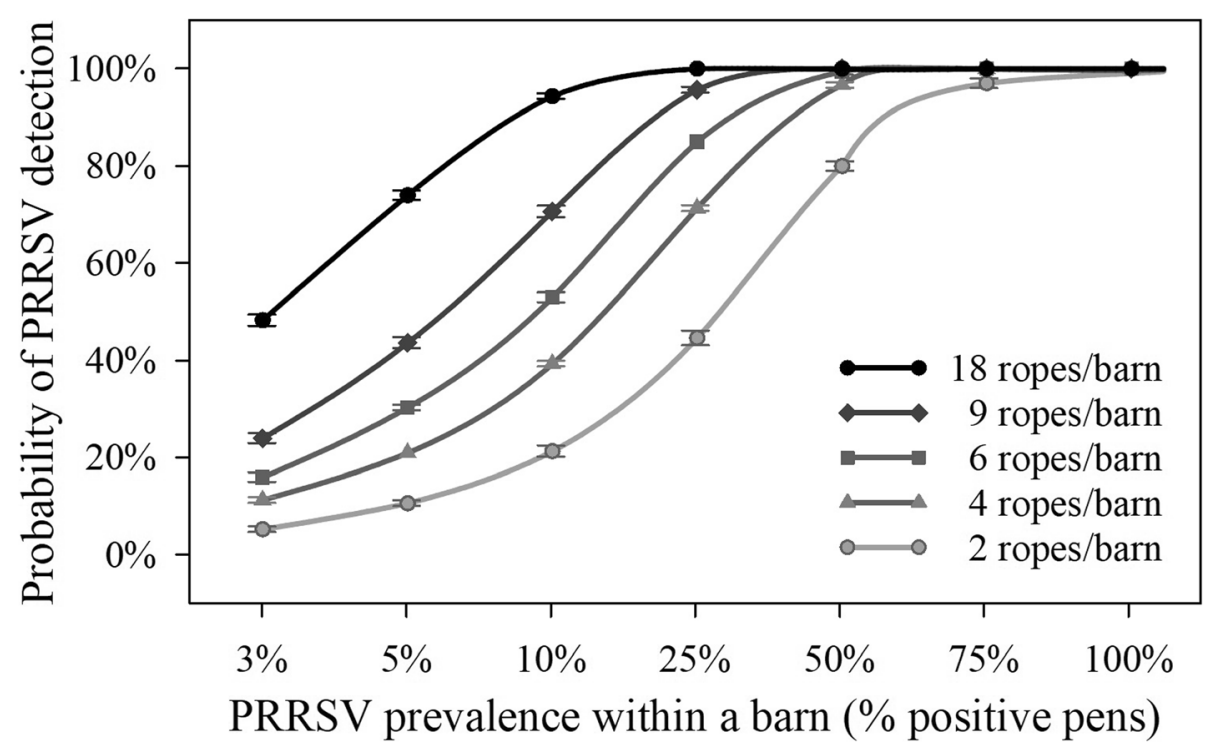

Fig. 3 Probability of PRRSV detection within a barn ( 1000 pigs) by pen prevalence and number of samples collected. Figure derived from data reported in Rotolo et al. (2017) [90]. Error bars represent the range of detection assuming assay diagnostic sensitivity of 95-100\%

When collected from a group of pigs, the aggregate and undiluted oral fluid samples represent such group of animals. Further pooling oral fluid samples collected within barns or on a production site is not recommended because of the potential for creating false negatives by diluting low concentrations of nucleic acids or antibody below the assay limit of detection, as is known to occur in serum [91]. Given a limited budget for surveillance, collecting fewer samples and establish their status with confidence is preferable to collecting a higher number of samples and pooling them.

Regardless of the number of samples collected, Rotolo et al., (2017) showed that fixed spatial sampling, i.e., spacing sampling points equidistant over the length of the barn, provided a higher probability of detection than random sampling. This reflects the spatially-dependent pattern of disease spread. That is, pathogens move from pig-to-pig and pen-to-pen; they are not randomly distributed within a barn [90].

In commercial systems, on-going site-level surveillance based on collecting a limited number of samples from all barns at fixed time intervals is preferable to collecting many samples sporadically [90]. A systematic approach provides real-time information on the dynamics of viral spread. For example, Ramirez et al. (2012) collected 6 oral fluids every 2 weeks from the same pens in 10 wean-to-finish barns on 10 different production sites for 18 weeks ( $n=600$ oral fluid samples, representing 12,150 pigs). Nucleic acid testing for PCV2, torque teno virus (TTV)1, TTV2, IAV, and PRRSV showed the presence of various combinations of viral infections on a continuous basis in all barns; albeit, the timing of infections was highly variable, even among barns in the same production system [64].

\section{Be an intelligent consumer}

Testing for surveillance is fundamentally different from testing to achieve a diagnosis. That is, diagnostic assays typically use cutoffs that find a balance between diagnostic sensitivity and diagnostic specificity (Youden Index). In contrast, surveillance assays must provide near-perfect diagnostic specificity (no false positives!) even at the cost of lower diagnostic sensitivity. This because false alarms trigger disruption in production and quickly poison the consumer's confidence in the surveillance system. In some cases, improvement in diagnostic specificity can be achieved with minimal impact on diagnostic sensitivity [92]. For example, in an evaluation of a PRRSV oral fluid ELISA ( $n=2205$ oral fluid samples), Henao-Diaz et al. (2020) found that changing the ELISA's cutoff from $S / P \geq$ 0.4 to $S / P \geq 1.0$ lowered diagnostic sensitivity from 99.7 to $96.2 \%$, but raised diagnostic specificity from 98.1 to $100 \%$ [93]. Pragmatically, this lowered diagnostic sensitivity represented $\mathrm{a}<3$ day delay in detection as the infected animals' antibody response reached $S / P \geq 1.0$. In the field, lower test sensitivity can be offset either by collecting more samples at each sampling or by using routine surveillance testing (every 2-4 weeks).

There are no perfect tests, but some tests are better than others. Thus, marked differences in diagnostic performance were reported among commercial PRRSV oral fluid antibody ELISAs and among IAV oral fluid RT-PCRs [24, 38] (Fig. 4). Since testing cannot be perfect, the use of statistical process control charting can be used provide a historical context for interpreting test results. In addition, have a plan in place for dealing with unexpected results. The plan may include retesting the original sample (in duplicate) and/or 


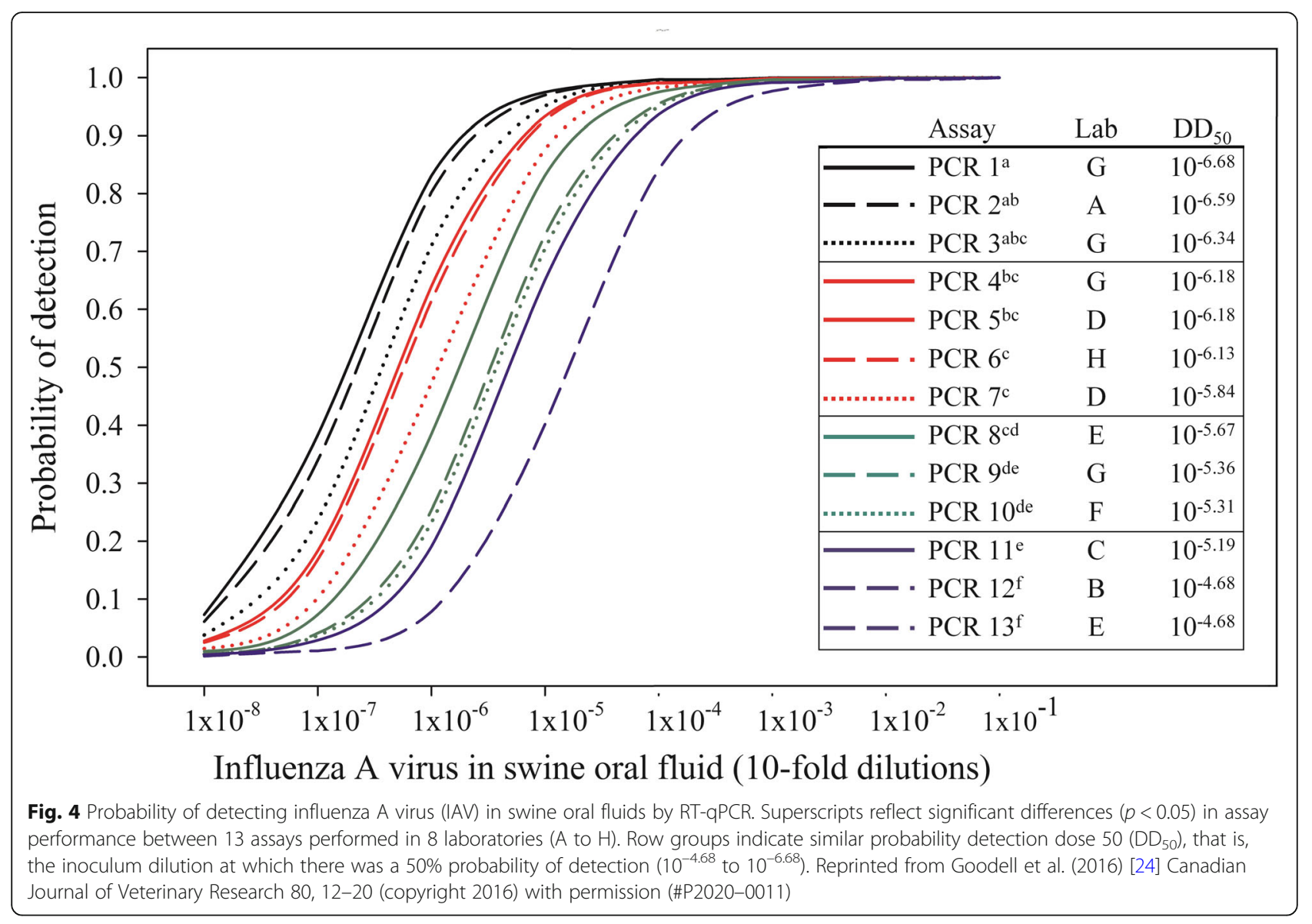

resampling the population. A robust confirmatory testing strategy can combine the strengths of both antibody and nucleic acid detection [66].

\section{Conclusions}

From an animal health perspective, larger pig populations combined with the extensive movement of pigs, people, and material between production sites produce conditions that promote the circulation of infectious diseases within/between farms $[4,5]$. These circumstances challenge our ability to prevent, control, and/or eliminate impactful swine pathogens. Disease management based on clinical observations is neither timely nor accurate; we require an active and systematic process that achieves the timely detection of pathogens and produces useful data that can guide management decisions. The last decade has seen significant advances in the routine use of aggregate specimens in surveillance, including oral fluids. Further improvements may be anticipated as additional diagnostic assays specifically adapted to the oral fluid matrix emerge and statistical refinements in the application of oral fluid sampling to populations are achieved.

\section{Abbreviations}

APPV: Atypical porcine pestivirus; ASFV: African swine fever virus:; CSFV: Classical swine fever virus; Diagnostic sensitivity: Probability that a positive test result comes from an infected pig; Diagnostic specificity: Probability that a negative test result comes from an uninfected pig; ELISA: Enzyme-linked immunosorbent assay; FMDV: Foot and mouth disease virus; IAV: Swine influenza A virus; HEV: Hepatitis E virus; Ig: Immunoglobulins; JEV: Japanese encephalitis virus; MLV: Modified live vaccine; PCR: Polymerase chain reaction; PCV: Porcine circovirus; PDCoV: Porcine delta coronavirus; PEDV: Porcine epidemic diarrhea virus; PHEV: Porcine hemagglutinating encephalomyelitis virus; PKV: Porcine kobuvirus; PPIV1: Porcine parainfluenza virus 1; PPV: Porcine parvovirus; PRCV: Porcine respiratory coronavirus; PRRSV: Porcine reproductive and respiratory virus; PRV: Pseudorabies virus (Aujeszky's); qPCR: Quantitative polymerase chain reaction; RT-PCR: Reverse transcription polymerase chain reaction; RT-qPCR or qRT-PCR: Reverse transcription quantitative polymerase chain reaction; SVA: Senecavirus A; SVDV: Swine vesicular disease virus;

TGEV: Transmissible gastroenteritis virus; TTV: Torque teno virus

\section{Acknowledgements}

AHD received support through Becas al Extranjero CONACyT, Mexico.

\section{Authors' contributions}

AHD and JZ wrote the main part of this paper. All authors have critically reviewed the manuscript, agreed fully to the content of the review, and approved the final manuscript.

\section{Authors' information}

AHD is a Ph.D. candidate focused in PRRSV epidemiology and diagnostics; LGL is an Associate Professor with expertise in infectious diseases and diagnostics technology development; DHB is the Serology Section Leader in 
lowa State University Veterinary Diagnostic Laboratory; and JZ is a Professor with expertise in swine infectious diseases.

\section{Funding}

Not applicable.

\section{Availability of data and materials}

Not applicable.

\section{Ethics approval and consent to participate}

Not applicable.

\section{Consent for publication}

Not applicable.

\section{Competing interests}

The authors declare no conflicts of interest regarding this publication.

Received: 18 June 2020 Accepted: 26 August 2020

Published online: 19 October 2020

\section{References}

1. Food and Agriculture Organization of the United Nations. FAOSTAT statistical database. FAO. 2020 [cited 2020 May 25]. Available from: http:// www.fao.org/faostat/en/\#data/QA.

2. Boender GJ, Van Den Hengel R, Van Roermund HJW, Hagenaars TJ. The influence of between-farm distance and farm size on the spread of classical swine fever during the 1997-1998 epidemic in the Netherlands. PLoS One. 2014;9:e95278.

3. Kinsley AC, Perez AM, Craft ME, Vanderwaal KL. Characterization of swine movements in the United States and implications for disease control. Prev Vet Med. 2019;164:1-9.

4. Schwabe C. The current epidemiological revolution in vet medicine. Part II Prev Vet Med. 1993;1:3-16

5. Schwabe $C$. The current epidemiological revolution in veterinary medicine Part I Prev Vet Med. 1982;1:5-15.

6. Nathues H, Alarcon P, Rushton J, Jolie R, Fiebig K, Jimenez M, et al. Cost of porcine reproductive and respiratory syndrome virus at individual farm level - an economic disease model. Prev Vet Med. 2017;142:16-29.

7. Wills RW, Zimmerman JJ, Yoon K-J, Swenson SL, Hoffman LJ, McGinley MJ, et al. Porcine reproductive and respiratory syndrome virus: routes of excretion. Vet Microbiol. 1997:57:69-81.

8. Lowe JF, Firkins LD, Banerjee M, Goldberg TL. A novel technique for the collection of ante mortem tonsil biopsies from alert swine. J Swine Heal Prod. 2003;11:229-32.

9. Tousignant SJP, Bruner L, Schwartz J, Vannucci F, Rossow S, Marthaler DG Longitudinal study of Senecavirus a shedding in sows and piglets on a single United States farm during an outbreak of vesicular disease. BMC Vet Res. 2017;13:1-5.

10. Pepin BJ, Kittawornrat A, Liu F, Gauger PC, Harmon K, Abate S, et al. Comparison of specimens for detection of porcine reproductive and respiratory syndrome virus infection in boar studs. Transbound Emerg Dis. 2015;62:295-304.

11. Goodell CK, Prickett J, Kittawornrat A, Zhou F, Rauh R, Nelson W, et al. Probability of detecting influenza a virus subtypes H1N1 and H3N2 in individual pig nasal swabs and pen-based oral fluid specimens over time. Vet Microbiol. 2013:166:450-60.

12. Hughes HR, Vincent AL, Brockmeier SL, Gauger PC, Pena L, Santos J, et al. Oral fluids as a live-animal sample source for evaluating cross-reactivity and cross-protection following intranasal influenza a virus vaccination in pigs. Clin Vaccine Immunol. 2015;22:1109-20.

13. Vosloo W, Morris J, Davis A, Giles M, Wang J, Nguyen HTT, et al. Collection of Oral fluids using cotton ropes as a sampling method to detect foot-andmouth disease virus infection in pigs. Transbound Emerg Dis. 2015;62:e71-5.

14. Stenfeldt C, Lohse L, Belsham GJ. The comparative utility of oral swabs and probang samples for detection of foot-and-mouth disease virus infection in cattle and pigs. Vet Microbiol. 2013;162:330-7.

15. Pepin B, Liu F, Main R, Ramirez A, Zimmerman J. Collection of oral fluid from individually housed sows. J Swine Heal Prod. 2015;23:35-7.
16. Henao-Diaz A, Ji J, Gimenez-Lirola L, Baum DH, Zimmerman J. Understanding and interpreting PRRSV diagnostics in the context of "disease transition stages.". Res Vet Sci. 2020;131:173-6.

17. Atkinson J, Dawes C, Ericson T, Fox P, Garndara B, Malamud D, et al. Guidelines for saliva nomenclature and collection. Ann N Y Acad Sci. 1993; 694:xi-xii.

18. Gutierrez A, Miller I, Hummel K, Nöbauer K, Martínez-Subiela S, Razzazi-Fazeli E, et al. Proteomic analysis of porcine saliva. Vet J. 2011;187:356-62.

19. Chiappin S, Antonelli G, Gatti R, De Palo EF. Saliva specimen: a new laboratory tool for diagnostic and basic investigation. Clin Chim Acta. 2007; 383:30-40.

20. Prickett KW, Simer R, Yoon K, Zimmerman J. Oral-fluid samples for surveillance of commercial growing pigs for porcine reproductive and respiratory syndrome virus and porcine circovirus type 2 infections. J Swine Heal Prod. 2008:16:86-91.

21. Prickett JR, Zimmerman JJ. The development of oral fluid-based diagnostics and applications in veterinary medicine. Anim Health Res Rev. 2010;11:207-16.

22. Olsen C, Karriker L, Wang C, Binjawadagi B, Renukaradhya G, Kittawornrat A, et al. Effect of collection material and sample processing on pig oral fluid testing results. Vet J. 2013;198:158-63.

23. Kittawornrat A, Prickett J, Wang C, Olsen C, Irwin C, Panyasing Y, et al. Detection of porcine reproductive and respiratory syndrome virus (PRRSV) antibodies in oral fluid specimens using a commercial PRRSV serum antibody enzyme-linked immunosorbent assay. J Vet Diagnostic Investig. 2012;24:262-9.

24. Goodell CK, Zhang J, Strait E, Harmon K, Patnayak D, Otterson T, et al. Ring test evaluation of the detection of influenza a virus in swine oral fluids by real-time reverse-transcription polymerase chain reaction and virus isolation. Can J Vet Res. 2016;80:12-20.

25. Gutierrez A, Ceron J, Fuentes-Rubio M, Tecles F, Beeley J. A proteomic approach to porcine saliva. Curr Protein Pept Sci. 2014;15:56-63.

26. Muneta Y, Yoshikawa T, Minagawa Y, Shibahara T, Maeda R, Omata Y. Salivary IgA as a useful non-invasive marker for restraint stress in pigs. J Vet Med Sci. 2010:72:1295-300

27. Baum B. Principles of saliva secretion. Ann N Y Acad Sci. 1993;694:17-23.

28. Kittawornrat A, Zimmerman JJ. Toward a better understanding of pig behavior and pig welfare. Anim Health Res Rev. 2010;12:25-32.

29. Prost K, Kloeze H, Mukhi S, Bozek K, Poljak Z, Mubareka S. Bioaerosol and surface sampling for the surveillance of influenza a virus in swine. Transbound Emerg Dis. 2019;66:1210-7.

30. Johnson J, Main R, Zimmerman J. Exogenous source of PRRSV antibody in positive oral-fluid ELISA results. J Swine Heal Prod. 2012:20:215.

31. Mestecky J. Saliva as a manifestation of the common mucosal immune system. Ann New York Acad Sci New. 1993;694:184-94.

32. Schroeder HW, Cavacini L. Structure and function of immunoglobulins. J Allergy Clin Immunol. 2010;125:S41-52.

33. Giménez-Lirola LG, Mur L, Rivera B, Mogler M, Sun Y, Lizano S, et al. Detection of African swine fever virus antibodies in serum and oral fluid specimens using a recombinant protein 30 (p30) dual matrix indirect ELISA. PLoS One. 2016;11:1-14.

34. Panyasing $Y$, Thanawongnuwech $R$, Ji J, Giménez-Lirola L, Zimmerman J. Detection of classical swine fever virus (CSFV) E2 and Erns antibody (lgG, $\lg A$ ) in oral fluid specimens from inoculated (ALD strain) or vaccinated (LOM strain) pigs. Vet Microbiol. 2018;224:70-7.

35. Panyasing Y, Goodell CK, Giménez-Lirola L, Kittawornrat A, Wang C, Schwartz KJ, et al. Kinetics of influenza a virus nucleoprotein antibody (lgM, $\lg A$, and $\lg G$ ) in serum and oral fluid specimens from pigs infected under experimental conditions. Vaccine. 2013;31:6210-5.

36. Prickett J, Johnson J, Murtaugh M, Puvanendiran S, Wang C, Zimmerman J, et al. Prolonged detection of PCV2 and anti-PCV2 antibody in oral fluids following experimental inoculation. Transbound Emerg Dis. 2011;58:121-7.

37. Kittawornrat A, Engle M, Panyasing Y, Olsen C, Schwartz K, Rice A, et al. Kinetics of the porcine reproductive and respiratory syndrome virus (PRRSV) humoral immune response in swine serum and oral fluids collected from individual boars. BMC Vet Res. 2013;9:61.

38. Henao-Diaz A, Giménez-Lirola L, Magtoto R, Ji J, Zimmerman J. Evaluation of three commercial porcine reproductive and respiratory syndrome virus (PRRSV) oral fluid antibody ELISAs using samples of known status. Res Vet Sci. 2019;125:113-8.

39. Decorte I, Van Breedam W, Van der Stede Y, Nauwynck HJ, De Regge N, Cay A. Detection of total and PRRSV-specific antibodies in oral fluids collected 
with different rope types from PRRSV-vaccinated and experimentally infected pigs. BMC Vet Res. 2014;10:134.

40. Rotolo ML, Giménez-Lirola L, Ji J, Magtoto R, Henao-Díaz YA, Wang C, et al. Detection of porcine reproductive and respiratory syndrome virus (PRRSV)specific IgM-lgA in oral fluid samples reveals PRRSV infection in the presence of maternal antibody. Vet Microbiol. 2018;214:13-20.

41. Bjustrom-Kraft J, Woodard K, Giménez-Lirola L, Rotolo M, Wang C, Sun Y, et al. Porcine epidemic diarrhea virus (PEDV) detection and antibody response in commercial growing pigs. BMC Vet Res. 2016;12:1-8.

42. Schwarz L, Riedel C, Högler S, Sinn LJ, Voglmayr T, Wöchtl B, et al. Congenital infection with atypical porcine pestivirus (APPV) is associated with disease and viral persistence. Vet Res. 2017;48:1-14.

43. Grau FR, Schroeder ME, Mulhern EL, Mclntosh MT, Bounpheng MA. Detection of African swine fever, classical swine fever, and foot-and-mouth disease viruses in swine oral fluids by multiplex reverse transcription realtime polymerase chain reaction. J Vet Diagnostic Investig. 2015;27:140-9.

44. Dietze K, Tucakov A, Engel T, Wirtz S, Depner K, Globig A, et al. Rope-based oral fluid sampling for early detection of classical swine fever in domestic pigs at group level. BMC Vet Res. 2017;13:2-7.

45. Senthilkumaran C, Yang M, Bittner H, Ambagala A, Lung O, Zimmerman J, et al. Detection of genome, antigen, and antibodies in oral fluids of pigs from pigs infected with foot-and-mouth disease virus. Can J Vet Res. 2017; 81:82-90.

46. Poonsuk K, Giménez-Lirola L, Zimmerman J. Development of a FMDV $3 A B C$ antibody ELISA for swine oral fluid specimens, SHIC final report; 2018. p. 1-10.

47. Plut J, Jamnikar-Ciglenecki U, Stukelj M. Molecular detection of porcine reproductive and respiratory syndrome virus, porcine circovirus 2 and hepatitis e virus in oral fluid compared to their detection in faeces and serum. Vet Res. 2020;16:1-8.

48. Panyasing Y, Goodell CK, Wang C, Kittawornrat A, Prickett JR, Schwartz KJ, et al. Detection of influenza a virus nucleoprotein antibodies in oral fluid specimens from pigs infected under experimental conditions using a blocking ELISA. Transbound Emerg Dis. 2014;61:177-84.

49. Lyons AC, Huang YJS, Park SL, Ayers VB, Hettenbach SM, Higgs S, et al. Shedding of japanese encephalitis virus in oral fluid of infected swine. Vector-Borne Zoonotic Dis. 2018;18:469-74.

50. Kasloff SB, Leung A, Pickering BS, Smith G, Moffat E, Collignon B, et al. Pathogenicity of Nipah henipavirus Bangladesh in a swine host. Sci Rep. 2019:9:1-11.

51. Wonziak A, Dagmara M, Piotr M, Stadejek T. Real-time PCR detection patterns of porcine circovirus type 2 (PCV2) in polish farms with different statuses of vaccination against PCV2. Viruses. 2019;2:2-17.

52. Guo Z, Li X, Deng R, Zhang G. Detection and genetic characteristics of porcine circovirus 3 based on oral fluids from asymptomatic pigs in Central China. BMC Vet Res. 2019;15:1-6.

53. Bai J. Development and evaluation of antibody detection assay for PCV3 virus [internet]. Kansas; 2020. Available from: https://www.swinehealth.org/ wp-content/uploads/2020/02/SHIC-diagnostic-assay-catalog-20Feb2020.pdf.

54. Homwong N, Jarvis MC, Lam HC, Diaz A, Rovira A, Nelson M, et al. Characterization and evolution of porcine deltacoronavirus in the United States. Prev Vet Med. 2016;123:168-74.

55. Mora-Díaz JC, Piñeyro PE, Houston E, Zimmerman J, Giménez-Lirola LG. Porcine hemagglutinating encephalomyelitis virus: a review. Front Vet Sci. 2019;6:1-12.

56. Gauger $P$. Validation of a real-time reverse transcription $P C R$ assay for detection of porcine kobuvirus (PKV) in porcine diagnostic samples. Ames; 2020. Available from: https://www.swinehealth.org/wp-content/uploads/202 0/02/SHIC-diagnostic-assay-catalog-20Feb2020.pdf.

57. Park JY, Welch MW, Harmon KM, Zhang J, Piñeyro PE, Li G, et al. Detection, isolation, and in vitro characterization of porcine parainfluenza virus type 1 isolated from respiratory diagnostic specimens in swine. Vet Microbiol. 2019 ; 228:219-25.

58. Milek D, Wozniak A, Guzowska M, Stadejek T. Detection patterns of porcine parvovirus (PPV) and novel porcine parvoviruses 2 through 6 (PPV2-PPV6) in polish swine farms. Viruses. 2019;11:1-13.

59. Magtoto R, Poonsuk K, Baum D, Zhang J, Chen Q, Ji J, et al. Evaluation of the serologic cross-reactivity between transmissible gastroenteritis coronavirus and porcine respiratory coronavirus using commercial blocking enzyme-linked immunosorbent assay kits. mSphere. 2019;4:1-12.

60. Decorte I, Van Campe W, Mostin L, Cay AB, De Regge N. Diagnosis of the Lelystad strain of porcine reproductive and respiratory syndrome virus infection in individually housed pigs: comparison between serum and oral fluid samples for viral nucleic acid and antibody detection. J Vet Diagnostic Investig. 2015;27:47-54.

61. Panyasing $Y$, Kedkovid R, Kittawornrat A, Ji J, Zimmerman J, Thanawongnuwech R. Detection of Aujeszky's disease virus DNA and antibody in swine oral fluid specimens. Transbound Emerg Dis. 2018;65: 1828-35.

62. Hole K, Ambagala T, Nfon C. Vesicular disease in pigs inoculated with a recent Canadian isolate of senecavirus a. Can J Vet Res. 2019;83:242-7.

63. Senthilkumaran C, Bittner H, Ambagala A, Lung O, Babiuk S, Yang M, et al. Use of oral fluids for detection of virus and antibodies in pigs infected with swine vesicular disease virus. Transbound Emerg Dis. 2017;64:1762-70.

64. Ramirez A, Wang C, Prickett JR, Pogranichniy R, Yoon KJ, Main R, et al. Efficient surveillance of pig populations using oral fluids. Prev Vet Med. 2012;104:292-300.

65. Mouchantat S, Haas B, Böhle W, Globig A, Lange E, Mettenleiter TC, et al. Proof of principle: non-invasive sampling for early detection of foot-andmouth disease virus infection in wild boar using a rope-in-a-bait sampling technique. Vet Microbiol. 2014;172:329-33.

66. Panyasing $Y$, Kedkovid R, Thanawongnuwech R, Kittawornrat A, Ji J, Giménez-Lirola L, et al. Effective surveillance for early classical swine fever virus detection will utilize both virus and antibody detection capabilities. Vet Microbiol. 2018;216:72-8.

67. Weesendorp E, Stegeman A, Loeffen W. Dynamics of virus excretion via different routes in pigs experimentally infected with classical swine fever virus strains of high, moderate or low virulence. Vet Microbiol. 2009;133:9-22.

68. Romagosa A, Gramer M, Joo HS, Torremorell M. Sensitivity of oral fluids for detecting influenza a virus in populations of vaccinated and non-vaccinated pigs. Influenza Other Respir Viruses. 2012;6:110-8.

69. Pierdon M, Martell A, Parsons T. Use of ropes to collect oral fluids from gestating sows housed in dynamic groups and fed via electronic sow feeder. J Swine Heal Prod. 2016;24:246-52.

70. Almeida MN, Rotto H, Schneider P, Robb C, Zimmerman JJ, Holtkamp DJ, et al. Collecting oral fluid samples from due-to-wean litters. Prev Vet Med. 2020;174:1-5.

71. lowa State University. Oral fluid collection in pigs [Internet]. The center of food security and publich health. 2015 [cited 2020 May 25]. Available from: http://www.cfsph.iastate.edu/video.php?link=oral-fluid-collection-in-pigs.

72. Almeida MN, Zimmerman JJ, Wang C, Linhares DCL. Assessment of abattoir based monitoring of PRRSV using oral fluids. Prev Vet Med. 2018;158:13745.

73. Boulbria G, Normand V, Leblanc-Maridor M, Belloc C, Berton P, Bouchet F, et al. Feasibility of pooled oral fluid collection from pre-weaning piglets using cotton ropes. Vet Anim Sci. 2020;9:100099 Available from: https:// linkinghub.elsevier.com/retrieve/pii/S2451943X20300120.

74. White D, Rotolo M, Olsen C, Wang C, Prickett J, Kittawornrat A, et al. Recommendations for pen-based oral-fluid collection in growing pigs. J Swine Heal Prod. 2014;22:138-41.

75. Pol F, Dorenlor V, Eono F, Eudier S, Eveno E, Liégard-Vanhecke D, et al. Individual and pen-based oral fluid sampling: a welfare-friendly sampling method for group-housed gestating sows. Prev Vet Med. 2017;147:58-65.

76. Prickett J, Simer R, Christopher-Hennings J, Yoon KJ, Evans R, Zimmerman J. Detection of porcine reproductive and respiratory syndrome virus infection in porcine oral fluid samples: a longitudinal study under experimental conditions. J Vet Diagnostic Investig. 2008;20:156-63.

77. Holmes A, Kittawornrat A, Goodell C, Panyasing Y, Hoff S, Subramanya K, et al. Behavioral aspects of oral fluid sample collection. In: Ellis R, editor. The 95th Annual Meeting of the CRWAD. Chicago: CRWAD; 2014. p. 138.

78. Henao-Díaz YA, Giménez-Lirola L, Poonsuk K, Cheng T-YY, Wang C, Ji J, et al. Effect of chemical clarification of oral fluids on the detection of porcine reproductive and respiratory syndrome virus lgG. J Vet Diagnostic Investig. 2018;30:1-7.

79. Prickett J, Cutler S, Kinyon J, Naberhaus N, Stensland W, Yoon K, et al. Stability of porcine reproductive and respiratory syndrome virus and antibody in swine oral fluid. J Swine Heal Prod. 2010;18:187-95.

80. Weiser AC, Poonsuk K, Bade SA, Gauger PC, Rotolo M, Harmon K, et al. Effects of sample handling on the detection of porcine reproductive and respiratory syndrome virus in oral fluids by reverse-transcription real-time PCR. J Vet Diagnostic Investig. 2018;30:807-12.

81. Decorte I, Van der Stede $Y$, Nauwynck H, De Regge N, Cay AB. Effect of saliva stabilisers on detection of porcine reproductive and respiratory 
syndrome virus in oral fluid by quantitative reverse transcriptase real-time PCR. Vet J. 2013;197:224-8.

82. Jones T, Muehlhauser V. Effect of handling and storage conditions and stabilizing agent on the recovery of viral RNA from oral fluid of pigs. J Virol Methods. 2014;198:26-31.

83. Linhares DCL, Rovira A, Torremorell M. Evaluation of Flinders technology associates cards for collection and transport of samples for detection of porcine reproductive and respiratory syndrome virus by reverse transcription polymerase chain reaction. J Vet Diagnostic Investig. 2012;24: 328-32.

84. Kittawornrat A, Panyasing Y, Goodell C, Wang C, Gauger P, Harmon K, et al. Porcine reproductive and respiratory syndrome virus (PRRSV) surveillance using pre-weaning oral fluid samples detects circulation of wild-type PRRSV. Vet Microbiol. 2014;168:331-9.

85. Gibert E, Martín-Valls G, Mateu E. Comparison of protocols for the analysis of type 1 porcine reproductive and respiratory syndrome virus by RT-PCR using oral fluids. J Virol Methods. 2017;243:190-5. Available from:. https:// doi.org/10.1016/j.jviromet.2017.02.010.

86. Dawson LL, Edwards SA. The effects of flavored rope additives on commercial pen-based oral fluid yield in pigs. J Vet Behav Clin Appl Res. 2015;10:267-71.

87. Seddon YM, Guy JH, Edwards SA. Optimising oral fluid collection from groups of pigs: effect of housing system and provision of ropes. Vet J. 2012; 193:180-4.

88. Mouchantat S, Globig A, Böhle W, Petrov A, Strebelow HG, Mettenleiter TC, et al. Novel rope-based sampling of classical swine fever shedding in a group of wild boar showing low contagiosity upon experimental infection with a classical swine fever field strain of genotype 2.3. Vet Microbiol. 2014; 170:425-9.

89. Olsen C, Wang C, Christopher-Hennings J, Doolittle K, Harmon KM, Abate S, et al. Probability of detecting porcine reproductive and respiratory syndrome virus infection using pen-based swine oral fluid specimens as a function of within-pen prevalence. J Vet Diagnostic Investig. 2013;25:328-35.

90. Rotolo ML, Sun Y, Wang C, Gimenez-Lirola L, Baum DH, Gauger PC, et al. Sampling guidelines for oral fluid-based surveys of group-housed animals. Vet Microbiol. 2017;209:20-9.

91. Rovira A, Cano JP, Muñoz-Zanzi C. Feasibility of pooled-sample testing for the detection of porcine reproductive and respiratory syndrome virus antibodies on serum samples by ELISA. Vet Microbiol. 2008;130:60-8.

92. Croft E, Blackwell T, Zimmerman J. Field application of a commercial porcine reproductive and respiratory syndrome virus (PRRSV) oral fluid antibody enzyme-linked immunosorbent assay (ELISA). Can Vet J. 2020;61:420-3.

93. He nao-Diaz A, Zhang M, Giménez-Lirola L, Gauger P, Baum D, Clavijo M, et al. Continual process improvement - the case of the PRRS oral fluid ELISA. In: Compendum 2020 North American PRRSV symposium. Chicago; 2020

\section{Publisher's Note}

Springer Nature remains neutral with regard to jurisdictional claims in published maps and institutional affiliations.

Ready to submit your research? Choose BMC and benefit from:

- fast, convenient online submission

- thorough peer review by experienced researchers in your field

- rapid publication on acceptance

- support for research data, including large and complex data types

- gold Open Access which fosters wider collaboration and increased citations

- maximum visibility for your research: over $100 \mathrm{M}$ website views per year

At BMC, research is always in progress.

Learn more biomedcentral.com/submissions 